\title{
Plasma patches inside the polar cap and auroral oval: the impact on the spaceborne GPS receiver
}

\author{
Chao Xiong ${ }^{1, *}$, Fan $\mathrm{Yin}^{2}$, Xiaomin $\mathrm{Luo}^{3}$, Yaqi Jin ${ }^{4}$, and Xin $\mathrm{Wan}^{2}$ \\ ${ }^{1}$ GFZ German Research Centre for Geosciences, Telegrafenberg, 14473 Potsdam, Germany \\ 2 Department of Space Physics, College of Electronic Information, Wuhan University, Luoyu Road 129, Wuhan, 430079 Hubei, PR China \\ ${ }^{3}$ GNSS Research Center, Wuhan University, Luoyu Road 129, Wuhan, 430079 Hubei, PR China \\ ${ }^{4}$ Department of Physics, University of Oslo, Oslo, Norway
}

Received 24 September 2018 / Accepted 24 June 2019

\begin{abstract}
In this study, we focus on plasma patches with very dense plasma in the southern hemisphere during the main phase of 2015 St. Patrick's Day storm. With in situ electron densities exceeding $1.5 \times 10^{12} \mathrm{~m}^{-3}$ at $450-500 \mathrm{~km}$ altitude, the patches cause strong signal outages of the global positioning system (GPS) receivers on board Swarm satellites. By using the field-aligned currents derived from the Swarm magnetic measurements, we determined whether the satellites fly inside the auroral oval or not. Different influences on the spaceborne GPS receiver are seen when these patches are located at different latitude regions, e.g., inside the polar cap or auroral oval. The simultaneously measurements of $2 \mathrm{~Hz}$ electron density as well as $50 \mathrm{~Hz}$ magnetic signatures from Swarm show that when large-scale polar cap patches transported from dayside lower latitude entering the cusp region, irregularities with much finer scale-size are generated; associated with various instabilities inside the cusp region, the small-scale irregularities cause much more severe influence on the GPS signals. This is the first direct evidence to show that when plasma patches are located inside the cusp region, the spaceborne receiver experiences stronger outage of GPS signals.
\end{abstract}

Keywords: Polar patch / scintillation / spaceborne receiver / GNSS / auroral oval

\section{Introduction}

Polar cap patches are "islands" of dense plasma, with typical horizontal extension from 100 to $1000 \mathrm{~km}$ at the high-latitude $\mathrm{F}$ region ionosphere. Since the detection of polar cap patches in the northern winter polar cap by using optical and ionosonde measurements (Hill, 1963; Buchau et al., 1983; Weber et al., 1984), other techniques such as the incoherent scatter radars (e.g., Pedersen et al., 2000; Carlson et al., 2002; Stolle et al., 2006a), in situ plasma density probed at altitude of low Earth orbit (LEO) satellites (e.g., Coley \& Heelis, 1995; Spicher et al., 2017, Chartier et al., 2018), as well as the ionospheric total electron content (TEC) measurements from the global navigation satellite system (GNSS) receivers installed at ground (e.g., Weber et al., 1986; Krankowski et al., 2006) or on board the LEO satellites (e.g., Noja et al., 2013; Chartier et al., 2018) are widely used for revealing the characteristics of polar cap patches.

\footnotetext{
*Corresponding author: bear@gfz-potsdam. de
}

Most polar cap patches are thought to originate when dayside solar illuminated ionospheric plasma to follow the flow streamlines of plasma convection pattern at high latitudes, move across the polar cap from the dayside to nightside, and sometimes they can exit the polar cap and enter the nightside auroral latitudes (e.g., Lockwood \& Carlson, 1992; Pedersen et al., 2000; Zhang et al., 2013a, 2015). The storm enhanced density (SED) (e.g., Foster, 1993) and related tongue of ionization (TOI) phenomena are attributed to be the major sources of polar cap patches (e.g., Foster et al., 2005; Hosokawa et al., 2010; Carlson, 2012). The soft particle precipitations at the cusp (Pinnock et al., 1993; Goodwin et al., 2015) or polar cap (Oksavik et al., 2006) cause regions with less intense ionization that sometimes have been also regarded as patches. In addition to geomagnetic storm periods, TOI can also occur during weakly disturbed or even geomagnetically quiet conditions, independent of SED occurrence (Liu et al., 2015, 2016). In this situation, the TOI tends to form during universal times when the high-latitude two-cell convection patterns are closer to the solarproduced middle-latitude plasma source region, facilitating the 
poleward plasma transportation. The plasma enhancements can present as a continuous TOI, or sometimes are segmented into pieces by the cusp flow channels and presents as discrete polar cap patches (e.g., Rodger et al., 1994; Valladares et al., 1994; Zhang et al., 2013b).

During their life time, the plasma patches can live for several hours and travel over thousands of kilometers. According to the observational location, the plasma patches have been named differently (Coley \& Heelis, 1998). For example, they have been termed as polar cap patches if they occur within the polar cap but as blobs if they occur outside the polar cap (Crowley, 1996; Crowley et al., 2000). By using observations from incoherent scatter radar as well as model simulations, Robinson et al. (1985) reported that after exiting the polar cap, the patches turned into blobs in the nightside auroral oval. Similar observation of polar cap patches turned to auroral blob during the geomagnetic storm on 21 March 1990 have also been reported by Crowley et al. (2000). Jin et al. (2014) have used auroral blobs for referring plasma patches inside the auroral oval (closed field line region), while using polar cap patches when occurring inside polar cap (open field line region). It is worth to separate plasma patches when they are located at different regions, as different mechanisms may be responsible for their generation and development. In addition, the patches may have different influence on the trans-ionospheric radio waves when they are locating at different latitude regions. Jin et al. (2014) provided a comparison of scintillation effect of global positioning system (GPS) related to three different types of structures at high latitudes: auroral arcs, polar cap patches, and auroral blobs. They found that the strongest phase scintillation is associated with auroral blobs, followed by polar cap patches and auroral arcs. Wang et al. (2016) found that the GPS phase scintillation is always larger than amplitude scintillation at the edges of the middle-latitude trough, SED, and polar cap patches, while inside the auroral oval the amplitude scintillation is much stronger than the phase scintillation. However, both studies revealed that much severer GPS signal scintillations happen at the auroral latitudes. The observations used in both studies are derived from the ground-based TEC, which is the integration of electrons along the line-of-sight (LOS) between GPS satellite and ground-based receiver. Therefore, the exact location of plasma irregularities along the LOS of upward-looking receivers is difficult to be identified. Instead, the LEO satellite provides continuous in situ measurements along its orbit. When the satellite flies through different latitude regions, for example, the auroral oval or polar cap, different influence can be observed from the onboard GPS receiver. Therefore, from this perspective the satellite observations may provide more detailed information of patches' influences on the GPS signals than the ground-based measurements.

Cherniak \& Zakharenkova (2016) reported very intense polar cap patches at the southern hemisphere during the 2015 St. Patrick's Day storm. The peak electron density of patches observed by the Swarm satellites reached as high as $1.5 \times 10^{12} \mathrm{~m}^{-3}$, and as a result the number of tracked GPS satellite has been reduced from eight to four for Swarm A at $450 \mathrm{~km}$, and the GPS signals were totally interrupted at all eight channels for Swarm B fling at $500 \mathrm{~km}$ altitude. However, our previous statistics about the GPS signal interruptions of three Swarm satellites showed that the plasma irregularities have stronger influence on the Swarm lower pair satellites, Swarm $\mathrm{A}$ and $\mathrm{C}$, as the irregularities usually have larger absolute density gradients at $450 \mathrm{~km}$ than that at $500 \mathrm{~km}$ (Xiong et al., 2016). Therefore, we are curious why for this specified event as reported by Cherniak \& Zakharenkova (2016), all satellites observed very intense plasma patches, the influence was more severe for the higher flying Swarm B rather than for Swarm A. In addition, this is the only one event of Swarm B with GPS signal interrupted at all eight channels at high latitude from 2014 to 2015 (see Fig. 2b of Xiong et al., 2016). Therefore, we have checked further the other instruments on board the Swarm satellites for this special event. The simultaneously magnetometer measurements of Swarm showed that the patches encountered by Swarm A were located inside the polar cap, and they have relative smooth variations in the plasma density; while the patches encountered by Swarm B were partly located inside the dayside auroral oval and were much more structured. The associated small-scale (less than $10 \mathrm{~km}$ ) irregularities with quite large absolute density gradients observed by Swarm B are possibly the reason to cause much more severe influence on the onboard GPS receiver. In the rest we are going to provide detailed comparison between the patches observed by the two Swarm satellites. Following the convention, we use polar cap patches when the plasma enhancements are observed inside the polar cap, while use plasma patches when they are observed outside the polar cap.

\section{Dataset}

The Swarm mission is composed of three identical satellites that were launched on 22 November 2013 into a near-polar orbit $\left(87.5^{\circ}\right.$ inclination $)$ with initial altitude of about $500 \mathrm{~km}$. Then the three satellites were maneuvered to the current constellation. The lower pair, Swarm A and C, is flying side-by-side at an altitude of about $470 \mathrm{~km}$, with longitudinal separation of $1.4^{\circ}$ (about $150 \mathrm{~km}$ ). And the third spacecraft, Swarm B, orbits the Earth at about $520 \mathrm{~km}$ with an inclination of $88^{\circ}$. Swarm A and $\mathrm{C}$ need about 133 days for covering 24 local time (LT) hours, and Swarm B needs about 141 days.

The Langmuir probes (LPs) on board Swarm satellites provide the in situ electron density and temperature measurements with a time resolution of $2 \mathrm{~Hz}$, and the data set from December 2013 to June 2016 has been compared with the coincident measurements of incoherent scatter radars, ionosondes, as well as Constellation Observing System for Meteorology, Ionosphere, and Climate (COSMIC) satellites (Lomidze et al., 2018). The result shows that the Swarm LPs systematically underestimate electron density by about $10 \%$, while overestimate the electron temperature by about $300-400 \mathrm{~K}$ and $700 \mathrm{~K}$ from the high- and low-gain LPs, respectively. In this study we focus more on the relative variations of electron density and temperature, therefore, the related issue of absolute values will not affect our results and interpretation. The dualfrequency GPS receivers on board the Swarm satellites are developed by RUAG space (Zangerl et al., 2014), with eight channels to receive signals from up to eight GPS satellites simultaneously. During the earlier mission period, all three Swarm satellites delivered GPS data with a time resolution of 


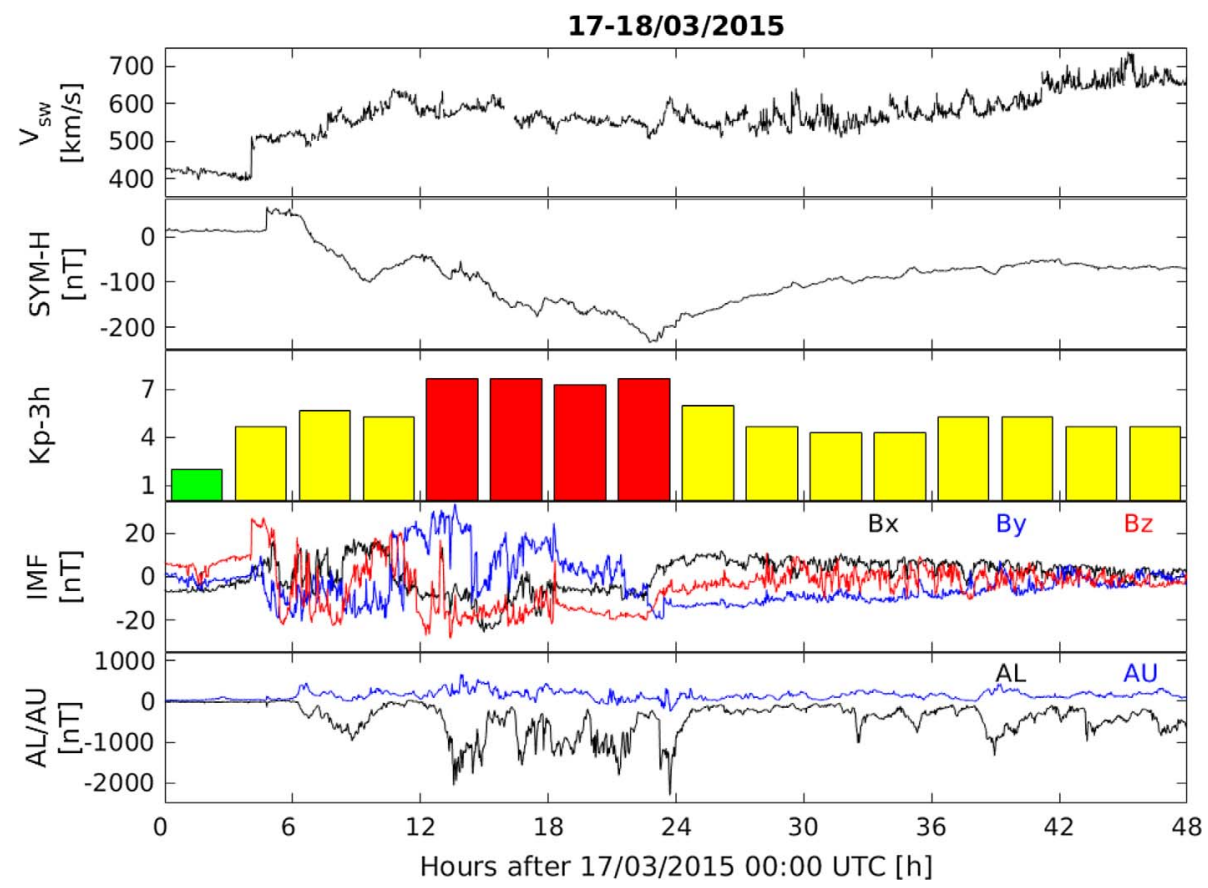

Fig. 1. Variations of solar wind, $S Y M-H$ index, three-hour $K_{p}$ index, three components of IMF as well as the auroral upper (AU) and lower (AL) indices on 17-18 March 2015.

10 s, but on 15 July 2014 the receiver configuration was changed and since then all Swarm satellites are delivering $1 \mathrm{~Hz}$ GPS measurements. More detailed information about the technical updates of Swarm on board receivers was described by van den Ijssel et al. (2016). In addition to the electron density and GPS measurements, the field-aligned currents (FACs), provided as one of the Swarm Level-2 products, have also been used.

Besides the Swarm in situ measurements, the global TEC map provided by the Madrigal database (Coster et al., 2003) with a time cadence of $5 \mathrm{~min}$, as well as the convection pattern from the SuperDARN observations (e.g., Greenwald et al., 1995; Chisham et al., 2007) are also used.

\section{Overview of the 2015 St. Patrick's Day storm}

The St. Patrick's Day storm was so far the largest storm occurring during the solar cycle 24 (minimum $S Y M-H$ value reached $-234 \mathrm{nT}$ ). The ionospheric responses as well as the plasma irregularities and related scintillation at low latitudes have been discussed by previous studies (e.g., Astafyeva et al., 2015; Carter et al., 2016; Zhou et al., 2016). Focusing at high latitudes, Liu et al. (2016) has compared the development of SED and TOI between measurements of global TEC map and model predictions. Strong scintillation on GPS signal (Cherniak et al., 2015; Prikryl et al., 2016; Jin \& Oksavik, 2018) and its consequences on precise point positioning (PPP) in Norway (Jacobsen \& Andalsvik, 2016) have also been reported. Good agreement was found between the in situ plasma irregularities at the LEO satellites altitudes and GPS scintillation at ground at both high latitudes (Cherniak \& Zakharenkova, 2016). Different to the above mentioned studies, we focus more on the plasma patches when they are located in or outside the polar cap, to see if different influence can be observed for the spaceborne GPS receiver.

To give an overview of the storm, Figure 1 (from top to below) shows the variations of solar wind speed $\left(V_{\mathrm{SW}}\right)$, $S Y M-H$ and global three-hour $K p$ indices, the $B_{x}, B_{y}$, and $B_{z}$ components of inter-planetary magnetic field (IMF) as well as auroral upper (AU) and lower (AU) indices on 17-18 March 2015. The storm starts with a sharp increase in $V_{\mathrm{SW}}$ from $420 \mathrm{~km} / \mathrm{s}$ to about $500 \mathrm{~km} / \mathrm{s}$ at 04:04 coordinated universal time (UTC) on 17 March, and afterwards it gradually increases and stays around $600 \mathrm{~km} / \mathrm{s}$ during the remaining time of storm. The sudden storm commencement (SSC) seen from SYM-H index with amplitude of $67 \mathrm{nT}$ appears at 04:48 UTC; then it gradually reduces indicating the storm main phase and reached the minima of $-224 \mathrm{nT}$ at 22:47 UTC; afterwards it starts to increase indicating the recovery phase, and fluctuations with smaller amplitudes are also seen in the IMF components. The three-hour $K_{p}$ index is always above four during the whole storm period, and maximum value exceeds seven at the storm main phase.

Abrupt changes are also seen in the IMF components on 17 March. Two intervals of strong southward $B_{z}$ (red line) are found between 05:00-09:00 and 12:00-24:00 UTC. With such IMF orientation, rapid reconnections at the dayside magnetopause are expected to happen. And following the $B_{z}$ southward turning, the AU/AL indices show also large fluctuations, indicating the presence of substorms due to the magnetotail reconnection. This transient reconnections happened on the 

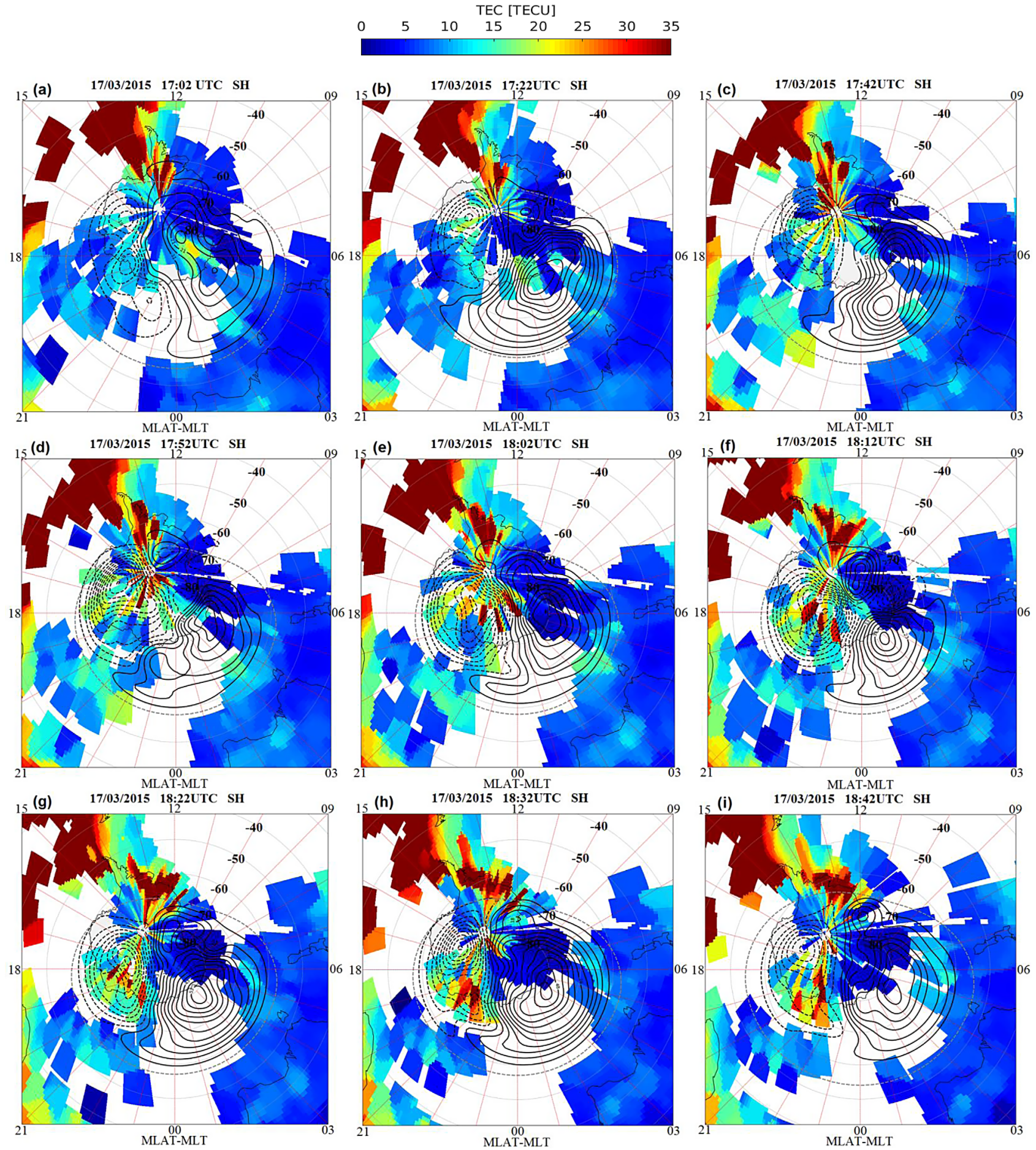

Fig. 2. Series of TEC maps as well as the ionospheric convection patterns in the geomagnetic latitude and magnetic local time coordinates. The convection patterns are provided by the SuperDARN observations.

magnetopause/magnetotail provide favorable conditions for the polar patch to enter/exit the polar cap (e.g., Lockwood \& Carlson, 1992; Pedersen et al., 2000; Zhang et al., 2013a). Therefore, patches with enhanced plasma density are expected to be observed during 12:00-24:00 UTC on 17 March, when long time southward $B_{z}$ persisted.

\section{Observations and discussions}

Figure 2 presents the ground-based TEC maps between 17:02-18:42 UTC on 17 March 2015. As the TEC enhancements at the northern high latitudes are not prominent during that time (not shown here, and readers are suggest to refer to 
the Figures 3 and 4 of Cherniak \& Zakharenkova, 2016), we focus on the southern hemisphere in the present study. At 17:02 UTC (Fig. 2a), feature of SED is observed originated from the dayside middle latitude (below $-50^{\circ}$ MLAT) between 12:00-14:00 magnetic local time (MLT), and the SED is entering the polar cap from the narrow throat region of the two convection cells. In addition, TEC enhancements of about 15-20 TECU are already found located inside the polar cap (most prominent for the dawnside convectional cell above $-80^{\circ}$ MLAT), which are possibly due to the previously formed polar cap patches as the $B_{z}$ persisting southward for the past a few hours. Twenty minutes later (Fig. 2b), the SED are found drifting deeper into the convection throat, and around 17:42 TUC (Fig. 2c) enhanced TEC is clearly seen entered into the polar cap. At 18:02 UTC (Fig. 2e), the enhanced plasma are seen totally separated from the SED at the convention throat, and form several discrete polar cap patches inside the polar cap with magnitude exceeding 35 TECU. In the rest evolution, these patches continue to drifting towards the nightside. One interesting feature of these discrete patches is that they are confined mainly at the duskside convection cell but do not enter the dawnside cell. Meanwhile, as the $B_{z}$ persists southward for long time, enhanced plasma are seen continuously entering into the polar cap from the dayside convection throat.

However, due to the lower resolution and data coverage of TEC maps in the southern hemisphere, we cannot see much more details about the polar cap patches when they enter the polar cap. In addition, as the TEC is the integration of electron density along the LOS between GPS satellite and receiver, it is difficult to identify whether the patches are already in or still outside the polar cap. Xiong et al. (2014) used the FACs derived from the Challenging Minisatellite Payload (CHAMP) satellite with scale length less than $150 \mathrm{~km}$ for identifying the auroral oval boundaries. Such an approach can also be applied to the Swarm FACs data to determine the auroral oval boundaries. Therefore, the simultaneous in situ measurements from multi-sensors on board the Swarm satellites provide a good opportunity for investigating whether the patches are located at different plasma regimes (auroral oval or polar cap).

Such an example is provided in Figure 3. Around 18:22 UTC on 17 March, Swarm A flies across the polar cap, and its trajectory (magenta dashed line) as well as the ground-based TEC map are shown in Figure 3a. As indicated by the arrow, Swarm A flies from the dawnside to duskside, and encounters TEC enhancements at about $-70^{\circ}$ MLAT around MLT noon hours, and the finest scale-size of TEC enhancements in the zonal extension are about several hundreds kilometers. Figure $3 \mathrm{~b}$ shows the in situ measurements of Swarm A during 18:09-18:30 UTC. The panels from top to bottom are the number of Swarm tracked GPS satellites, Rate of Change of TEC Index (ROTI), electron density and temperature, as well as the FAC signatures with scale-length less than $150 \mathrm{~km}$. Sust et al. (2014) found that during GPS loss-lock incidents, the Swarm onboard GPS receiver showed violent phase scintillation but with no discernable fluctuations on the signal amplitude, therefore, here we show only the ROTI index derived from carrier phases, which is defined as the standard deviation of the rate of slant TEC with a moving window of 1 min interval (Pi et al., 1997). The auroral oval determined from the FAC signatures are indicated by shadowed rectangles on the dawnside and duskside, respectively.
Within the auroral oval at both pre-noon and afternoon sides, the electron temperature is largely enhanced by more than $3000 \mathrm{~K}$, due to the energetic particle precipitation (Weber et al., 1989; Crain et al., 1994). We would like to note that the absolute value of electron temperature derived from Swarm is still under calibration (Lomidze et al., 2018), but here we are focusing more on its relative fluctuations. The electron density inside the auroral oval at pre-noon side shows also enhancements but with very low absolute magnitude (around $1 \times 10^{11} \mathrm{~m}^{-3}$ ), while inside the auroral oval at the afternoon side, the electron density are found to show some decreases (see the two electron density reduction regions around 18:24 UTC), but also with absolute magnitude of $1 \times 10^{11} \mathrm{~m}^{-3}$. With such low density gradients, the GPS signals are less disturbed at both auroral regions and no clear reductions are seen in the tracked GPS satellite number. However, a region with strong density enhancement of about $1.5 \times 10^{12} \mathrm{~m}^{-3}$ are observed around 18:20 UTC between the two auroral oval regions, indicating that it is located right inside the polar cap. Such intense polar cap patch is 10 times larger than the surrounding background electron density, and its outer shape has a scale-length of about $650 \mathrm{~km}$ along the satellite track. In addition, small-scale depletions about tens of $\mathrm{km}$ are also seen embedded on both walls of the polar cap patch. These small-scale irregularities are possibly the reason to cause clear fluctuations of the ROTI values and further result the tracked GPS satellites of Swarm A reducing from eight to four. The electron temperature slightly reduces by about $500 \mathrm{~K}$ within the density enhancement, indicating that the density enhancement is caused by transportation but not due to the particle precipitation (e.g., Coley \& Heelis, 1995; Stolle et al., 2006a; Zou et al., 2016).

Half an hour later, Swarm B flies through almost the same region with enhanced TEC (Fig. 3c). Compared to Swarm A, the trajectory of Swarm B is more aligned in the noon-midnight direction. The in situ electron density of Swarm B shows also intense enhancements around 18:51 UTC (Fig. 3d) and the absolute magnitude exceeds $1.5 \times 10^{12} \mathrm{~m}^{-3}$. The outer shape of the patch-group covers about $1800 \mathrm{~km}$ along the orbit of Swarm B, but the plasma show rapid fluctuations with scale-size of a few $\mathrm{km}$. The enhanced FAC signatures indicate that the Swarm B observed plasma patch partly located inside the noon side auroral oval (around 12:26 MLT, possibly in the cusp region). A reduction of the electron temperature (by about $800 \mathrm{~K}$ ) is first seen inside the polar patches, and then is largely enhanced (over $4000 \mathrm{~K}$ ) when Swarm is inside the cusp. It also indicates that the plasma patch with such dense density is not produced by the precipitation alone, but due to the photoionization plasma from dayside lower latitudes been transported into the cusp region, which is also evidenced from the TEC map. As intense small-scale irregularities adding on the large-scale plasma patch, strong fluctuations are also seen in the ROTI of Swarm B, and the GPS signal interruptions happen at all eight channels. The epochs with tracked GPS satellite less than four are marked with red color. The total signal outage lasts for as long as three minutes. It is worth noting that due to the precipitation induced failure of the Swarm onboard star cameras (used for the satellite attitude determination), a short interruption is resulted in the magnetometer measurements around 18:54 UTC. Inside the polar cap and auroral oval at night side, no further intense electron density enhancements are observed by Swarm B. 

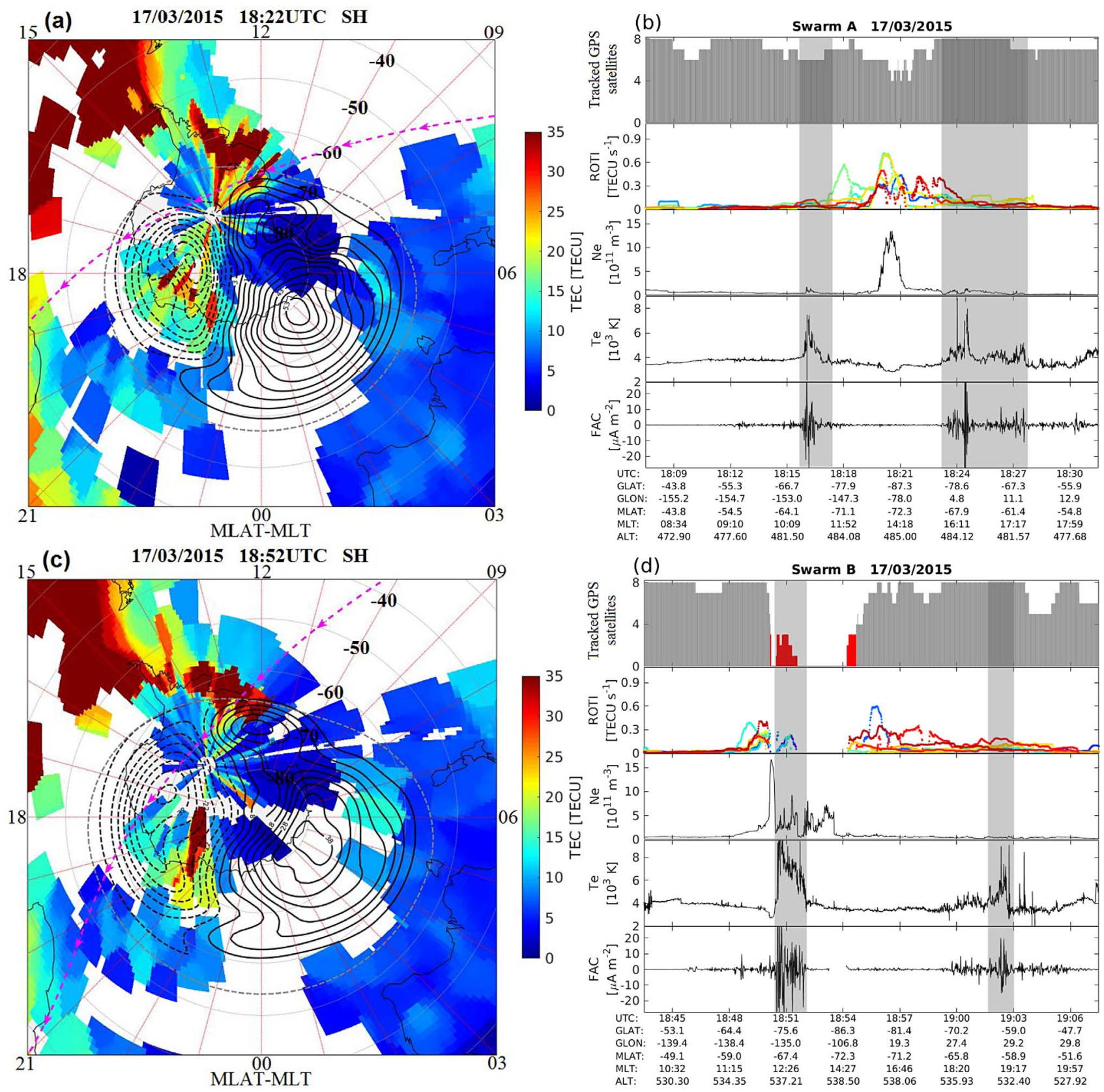

Fig. 3. (a) TEC map as well as the ionospheric convection pattern around 18:22 UTC on 17 March 2015. The orbital track of Swarm A is indicated by the magenta dashed line. (c) In situ measurements from Swarm A from 18:07 to 18:32 UTC, and the panels from top to bottom are the total number of tracked GPS satellites, ROTI, in situ electron density and temperature, as well as the small-scale FACs signatures $(<150 \mathrm{~km})$. (c) and (d) are in a similar format as for (a) and (b), but for Swarm B measurements around 18:52 UTC.

The Swarm onboard Langmuir probe provides $2 \mathrm{~Hz}$ resolution. Assuming the vehicle orbital speed of $7.5 \mathrm{~km} / \mathrm{s}$ and according to the Nyquist sampling theorem, the measured in situ electron density reflects the smallest structure of scale-size of $7.5 \mathrm{~km}$. However, the $16 \mathrm{~Hz}$ electron density data measured by the thermal ion imager of Swarm are not available during the time of interest. A recent paper from Laundal et al. (2019) found that the previously reported diamagnetic current at the equatorial region (Lühr et al., 2003; Stolle et al., 2006b) appears to be a ubiquitous phenomenon also at polar latitudes. They showed that the small perturbations of the Swarm magnetic measurements are anti-correlated with the plasma density measured by Langmuir probe. Therefore, we use also the $50 \mathrm{~Hz}$ magnetic measurements from Swarm to check if structures of scale-size less than $7.5 \mathrm{~km}$ can be observed associated with the patches.

Figure 4 shows the detailed variation of $2 \mathrm{~Hz}$ electron density as well as $50 \mathrm{~Hz}$ magnetic residuals for Swarm A and B, respectively, focusing only the regions of plasma patches as shown in Figure 3. The geomagnetic field contributions from 

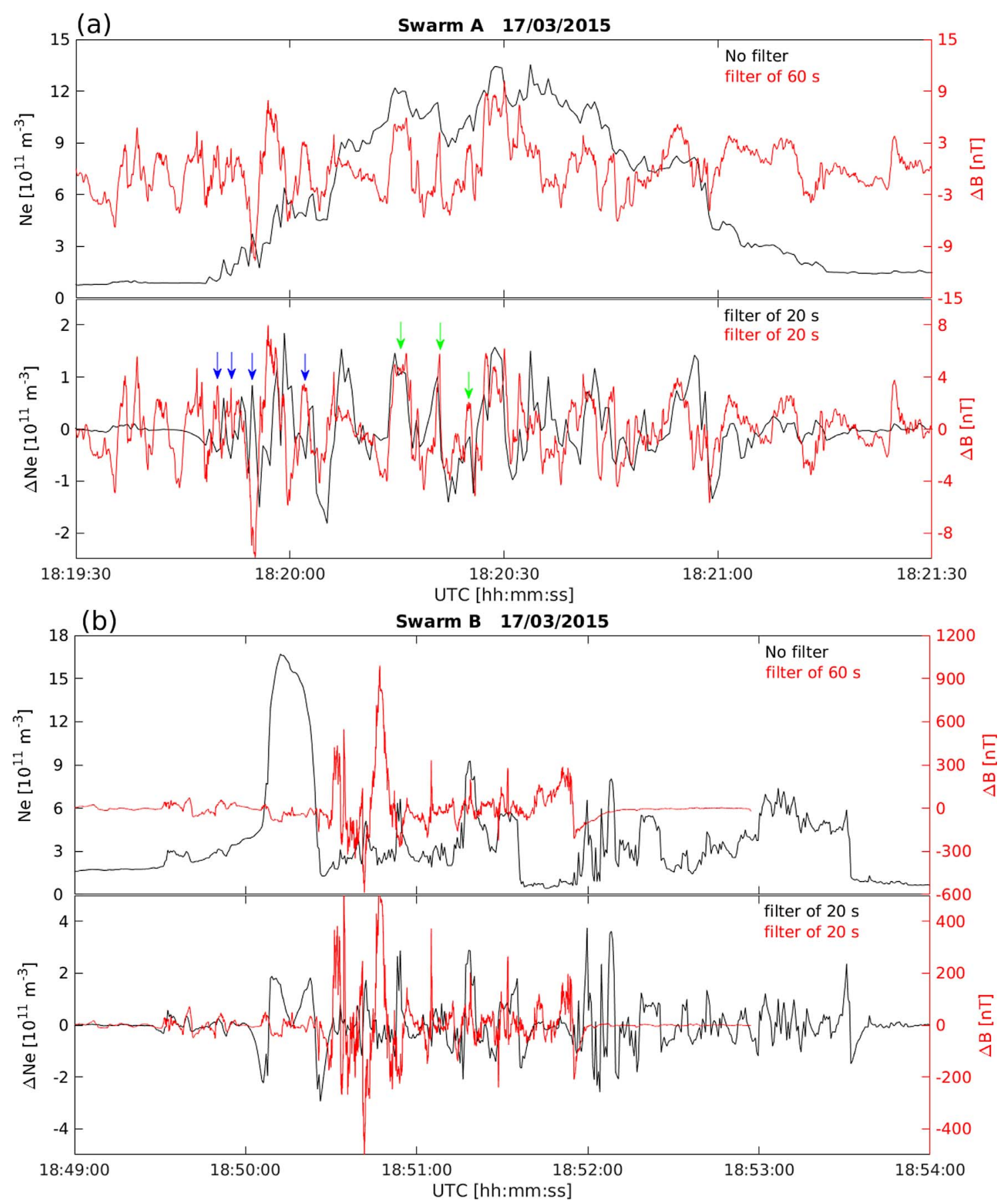

Fig. 4. (a) Detailed variations of $2 \mathrm{~Hz}$ electron density (black line) as well as the $50 \mathrm{~Hz}$ high-pass filtered magnetic residual within the polar cap patches observed by Swarm A. Filters of different cut-off frequencies have been applied to the data. (b) As similar as in (a), but for the observations from Swarm B.

the Earth's core, crust, and magnetosphere have to be first removed from the Swarm $50 \mathrm{~Hz}$ magnetic measurements. The three sources of geomagnetic fields are represented by the CHAOS-6 model (Finlay et al., 2015). By doing the subtraction, we isolate magnetic field variations originating from the ionosphere. A high-pass filter with cut-off period of $60 \mathrm{~s}$ (corresponds to $450 \mathrm{~km}$ ) has been first applied to the magnetic residual, in order to removes large-scale variations that are possibly not related to the polar cap patches (Park et al., 2012), and then the small-scale magnetic perturbations are seen. The black line in the top panel of Figure 4a shows the $2 \mathrm{~Hz}$ electron density data, and the small-scale plasma variations of a few tens $\mathrm{km}$ embedded on the large-scale polar cap patches are also evidenced. We have also tried high-pass filter with cut-off period longer than $60 \mathrm{~s}$ to the magnetic residual, however, no equivalent scale-size diamagnetic perturbations can be observed 
associated to the large-scale plasma structure (about $650 \mathrm{~km}$ ), even though the plasma density of polar cap patch is 10 times larger than the background.

Lühr et al. (2003) used the currents flowing perpendicular to the pressure gradient and the ambient magnetic field to explain the diamagnetic effect of plasma. The pressure gradient driven current, $j$, can be written as:

$$
j=-k / B^{2}\left\{\nabla\left[n\left(T_{i}+T_{e}\right)\right]\right\} \times \boldsymbol{B}
$$

where $k$ is the Boltzmann constant, $T_{e}$ and $T_{i}$ are the electron and ion temperatures, $n$ is the electron density and $\boldsymbol{B}$ the magnetic field vector with its magnitude $B$. By assuming an isotropic pressure and local thermodynamic equilibrium, the magnetic variation dominated by the plasma density gradient can be obtained (Laundal et al., 2019):

$$
\nabla B=-k \mu_{0} \frac{T_{i}+T_{e}}{B} \nabla n
$$

where $\mu_{0}$ is the vacuum permeability. From equation (2) we see that the variation of magnetic residual depends not only on the plasma density gradient, but also on the gradients of electron and ion temperatures. As already shown in our Figure $3 \mathrm{~b}$, the electron temperature within the polar cap patch is reduced by about $500 \mathrm{~K}$, which partly balance the pressure caused by the enhanced plasma gradient, and as a result no large-scale magnetic perturbation is seen within the polar cap patches. While, for the example shown in the Figure 1 of Laundal et al. (2019), the electron temperature variation is much smoother than that in our case, therefore, the magnetic residual is well anti-correlation to the plasma gradient. From statistics, they also pointed out that the diamagnetic effect at high latitudes mainly dominates magnetic residual field intensity variations at scale-size of a few tens kilometers.

To focus on the smaller-scale magnetic field variations, a filter with cut-off period of $20 \mathrm{~s}$ has been applied to both the magnetic residual as well as the electron density, and the result is shown in bottom panel of Figure 4a. For some parts (see the regions indicated by blue arrows), the $\Delta B$ is anti-correlated with $\Delta N e$, while from time to time the magnetic and plasma perturbations show also in-phase variations (see the regions indicated by green arrows), indicating that other processes (e.g., Heilig et al., 2007), rather than the diamagnetic currents, dominate the magnetic residual variations at these regions.

Another interesting feature seen here is that the polar cap patch at the first edge around 18:20:00 UTC seems to have smaller scale-size than that at the second edge around 18:21:00 UTC. As the Swarm A flies from the morning to afternoon sector (see Fig. 3a), the first edge is located closer to the noon-side auroral latitude, while the second edge is located deeper into the polar cap. Goodwin et al. (2015) reported an event of polar cap patches with smaller amplitude caused by particle precipitation, which show much finer scale-size structures at the cusp region while following the convection further into polar cap the small-scale structures become less structured. The example showed in our study has similar characteristic, although the polar cap patch observed by Swarm A is not caused by the particle precipitation, but due to the dayside solar illuminated ionospheric plasma being transported into polar cap. When entering the cusp, particle precipitations will work on the large-scale plasma patches, generating small-scale irregularities.
This assumption also explains well why parts of the plasma patches observed by Swarm B are much structured when they are located in the cusp region (after 18:50:25 UTC in Fig. 4b); but for the parts (between 18:50:00 and 18:50:25 UTC) having not yet entering the cusp, the plasma shows only smooth variation even although with strong absolute gradient. It is also worth noting that inside the auroral oval, the intensity of $\Delta B$ becomes almost 100 times larger than that in the polar cap regions, due to the largely enhanced FACs and horizontal currents at auroral oval; and as the thermodynamic equilibrium condition is not satisfied inside auroral oval, the magnetic perturbation is therefore not dominated by the plasma pressure gradient.

Jin et al. $(2014,2016)$ pointed out that within the auroral latitudes there are various instabilities driven by free energies, e.g. the gradient drift instability, shear-driven (KelvinHelmholtz) instability, etc. (Kersley et al., 1988; Keskinen et al., 1988; Carlson et al., 2008; Moen et al., 2012). The enhanced electron densities probed by Swarm B reach $1.5 \times 10^{12} \mathrm{~m}^{-3}$ (as almost the same magnitude of Swarm A) before the satellite flies inside the noon-side auroral latitude (cusp), and the densities suddenly decrease to lower magnitudes but with much finer structures when the satellite enters the cusp. Carlson et al. (2008) proposed that the shear-driven instability first rapidly structures the enhanced plasma when entering the cusp, after which the gradient drift instability works on the large-scale structures created by the shear-driven instability, and produces smaller scale irregularities. The largest plasma density gradient observed by Swarm B between 18:50:00 and 18:50:25 UTC probably corresponds to the edge of cusp, where reconnections at the magnetopause lead to strong flow shears. These strong flow shears in turn very rapidly pre-structure the newly entering patches which then can cause severe scintillation scale structures instantly within an order of a minute (Carlson et al., 2008; Moen et al., 2012). As the plasma patch observed by Swarm B is just entering the cusp region, the original photoionization plasma with large-scale (see the sharp wall at the equatorward edge of cusp but without small-scale irregularities) is then possibly intensely structured by the strong flow shears. St.-Maurice \& Hanson (1982) as well as Carlson (2012) pointed out that the enhanced plasma flow velocity during storm could also cause strong ion-frictional heating and enhanced ion temperature and the enhanced ion temperature can cause rapid recombination of the ionosphere and deplete the electron density (Rodger et al., 1992). This may explain the reduced plasma density inside cusp observed by Swarm B around 18:51 UTC. The example shown in Figure 3d also suggests that at the cusp region the plasma patch have sharper gradient at the auroral equatorial boundary compared to poleward boundary.

In fact, the GPS signal interruptions at some channels of Swarm satellites happened several times during the 2015 St. Patrick's Day storm. Taken Swarm A for example, Figure 5a presents (top) the tracked GPS satellite number and (bottom) the in situ electron density along its orbits on 17-18 March. During most of the time, Swarm A keeps tracking with six or more GPS satellites, but there are also periods when tracked GPS satellites reduce to less than four (indicated by the red asterisks and marked with "PA" to "PG") or even total signal interruption happened at all channels. Three periods, "PA", "PB", and "PD" are found when Swarm A at low latitudes, 


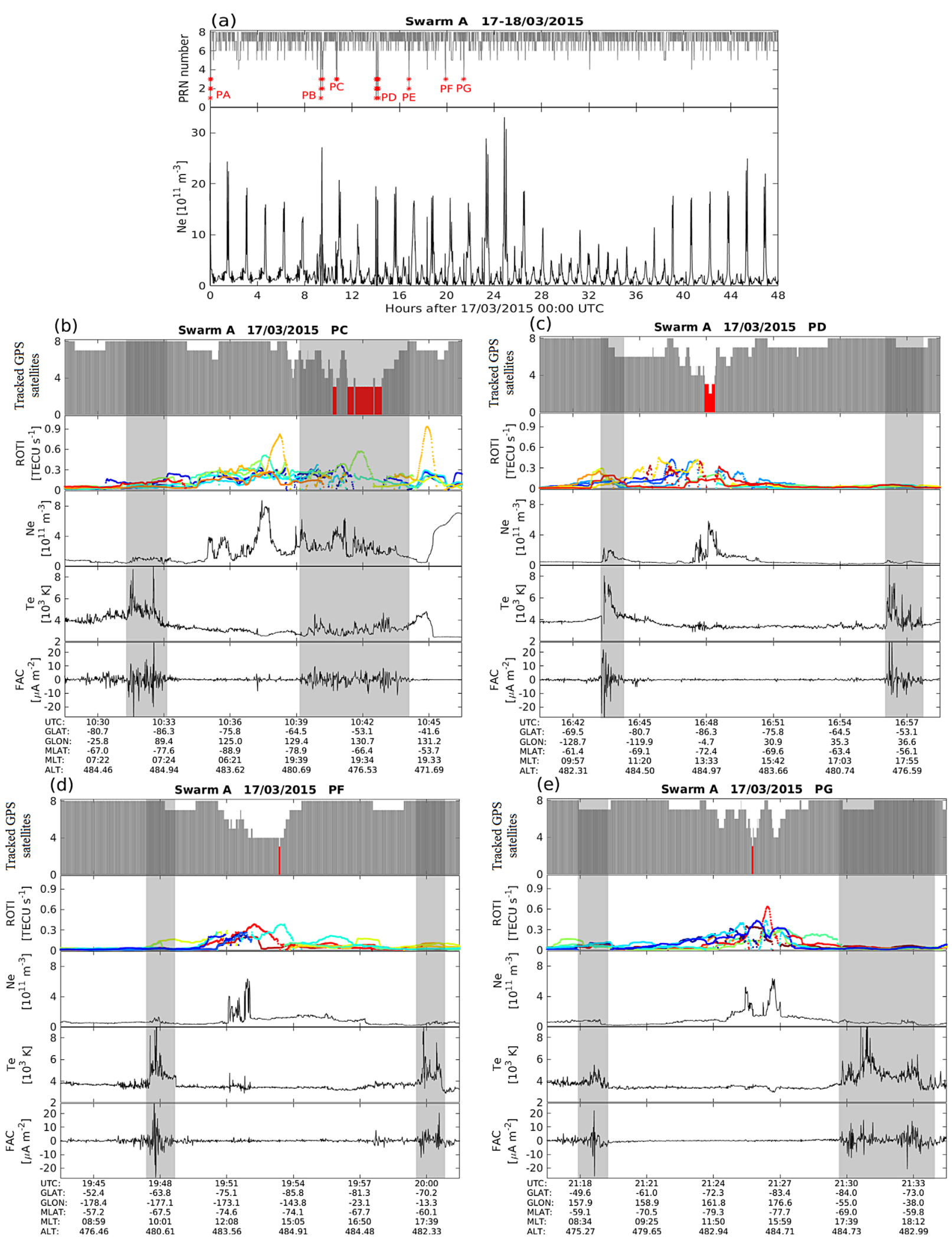

Fig. 5. (a) Swarm A (top) tracked GPS satellite number and (bottom) in situ electron density measurements along its orbits on 17-18 March 2015. There are seven periods when Swarm A tracked GPS satellite number less than four, and they are indicated by red asterisks and marked as periods PA to PG. The detailed variations of tracked GPS satellite number, ROTI, in situ electron density and temperature, as well as the small-scale FAC profiles of Swarm A for four periods at high latitudes when tracked GPS satellite less four (indicated by red color in the top frame) are observed. 
and the GPS signal interruption are caused by the post-sunset equatorial plasma irregularities as already been reported by Xiong et al. (2016, 2018). At high latitudes, there are also four periods, marked with "PC", "PE", "PF", and "PG", when the tracked GPS satellite numbers are less than 4 . The much more detailed observations are shown in Figure 5b-e, and we see the epochs of reduced GPS satellite tracked are all associated with enhanced small-scale plasma irregularities observed in the in situ electron density of Swarm. When there are only polar patches observed at the auroal oval but with very low absolute magnitude (only caused by the particle precipitations), e.g., around 10:32 UTC of Figure 5b, 16:44 and 16:57 UTC of Figure 5c, 19:48 and 20:00 UTC of Figure 5d, as well as 21:19 and 21:31 UTC of Figure 5e, ROTI values show really small fluctuations and almost no reductions are seen in the tracked GPS satellite number. Larger fluctuations of ROTI and clear reduction of tracked GPS satellite are seen when Swarm A encounters polar cap patches of large absolute enhancement inside the polar cap, for example, around 10:39 UTC of Figure 5b, 16:48 UTC of Figure 5c, 19:51 UTC of Figure 5d and 21:26 UTC of Figure 5e, and all these polar cap patches are found with embedded small-scale (tens of $\mathrm{km}$ ) plasma irregularities. As shown in Figure 5b when the polar patch has been transported inside the aurora oval at nightside (around 19:34 MLT), GPS signal interruption at some channels are also seen; around 10:45 UTC, when Swarm flies through the middle latitude trough, large gradient due to sharp decrease of electron density causes also significant phase scintillation of the GPS signal, but due to a lack of small-scale irregularities associated with the middle latitude trough, no prominent reduction of the tracked GPS satellite number is observed.

\section{Summary}

In this study, we focus on the polar patches of very dense plasma when they are located inside the polar cap and auroral oval. Their associated small-scale irregularities and impacts on the GPS receiver on board Swarm satellites have been discussed. The main findings are summarized as:

1. During the 2015 St. Patrick's Day storm, the polar patches at the southern hemisphere show values exceeding 35 TECU in the ground-based TEC, and the in situ electron densities measured by Swarm satellites at $450-500 \mathrm{~km}$ reach above $1.5 \times 10^{12} \mathrm{~m}^{-3}$.

2. The polar cap patches encountered by Swarm A inside the polar cap, cause the tracked GPS satellite number reducing from eight to four; while with similar magnitude of dense plasma, the plasma patches encountered by Swarm B at the cusp region cause GPS signal loss at all eight channels.

3. The $50 \mathrm{~Hz}$ magnetic signatures from the Swarm satellites show that the large-scale plasma gradient (hundreds of kilometers) do not cause prominent magnetic perturbations of equivalent scale-size, possibly due to the reduced electron temperature inside the polar cap patches.

4. Our result shows that when the large-scale photoionization plasma transported from dayside lower latitude to the cusp region, irregularities with much finer scale-size are generated; while following the convection further into the polar cap, the small-scale structures become less structured. Associated with various instabilities at the cusp region, they have much more severe influence on the GPS signal.

Acknowledgements. The authors want to thank Dr. Claudia Stolle and Dr. Juan S. Rodriguez-Zuluaga for the fruitful discussion. The solar wind and IMF data are derived from the NASA's ACE mission, and they can be downloaded at the website of http://www.srl.caltech.edu/ACE/ASC/level2/. The $S Y M-H$ data are provided by the world data center for geomagnetism, Kyoto (http://wdc.kugi.kyoto-u.ac.jp/aeasy/ index.html). The three-hour $K_{p}$ index is derived from the GFZ German Research Centre for Geosciences (https://www. gfz-potsdam.de/en/kp-index/). The European Space Agency (ESA) is also acknowledged for providing the Swarm data (http://earth.esa.int/swarm). The Virginia Tech SuperDARN Research Group for providing the SuperDARN potential maps (http://vt.superdarn.org/tiki/tiki-print.php?page=ASCIIData). GPS TEC data products and access through the Madrigal distributed data system (http://cedar.openmadrigal.org/ftp/) are provided to the community by the Massachusetts Institute of Technology under support from U.S. National Science Foundation grant AGS-1762141. Data for TEC processing is provided from the following organizations: UNAVCO; Scripps Orbit and Permanent Array Center; Institut Geographique National, France; International GNSS Service; The Crustal Dynamics Data Information System (CDDIS); National Geodetic Survey; Instituto Brasileiro de Geografia e Estatística; RAMSAC CORS of Instituto Geogáfico Nacional de la República Argentina; Arecibo Observatory; Low-Latitude Ionospheric Sensor Network (LISN); Topcon Positioning Systems, Inc.; Canadian High Arctic Ionospheric Network; Institute of Geology and Geophysics, Chinese Academy of Sciences, China Meteorology Administration; Centro di Ricerche Sismologiche; Système d'Observation du Niveau des Eaux Littorales (SONEL); RENAG: REseau NAtional GPS permanent; GeoNet, the official source of geological hazard information for New Zealand; GNSS Reference Networks; Finnish Meteorological Institute; and SWEPOSSweden.

Chao Xiong is partly supported by the Swarm Data, Innovation, and Science Cluster (DISC) projects found by ESA (Grant No. 4000109587/13/I-NB), and Yaqi Jin is supported by the Research Council of Norway under grant 275655. The work of Fan Yin is supported by the National Natural Science Foundation of China (Grant Nos. 41474157).

The editor thanks two anonymous referees for their assistance in evaluating this paper.

\section{References}

Astafyeva E, Zakharenkova I, Förster M. 2015. Ionospheric response to the 2015 St. Patrick's Day storm: A global multi-instrumental overview. J Geophys Res Space Phys 120: 9023-9037. DOI: 10.1002/2015JA021629. 
Buchau J, Reinisch BW, Weber EJ, Moore JG. 1983. Structure and dynamics of the winter polar cap F region. Radio Sci 18: 995-1010. DOI: 10.1029/RS018i006p00995.

Carlson H, Oksavik K, Moen J, van Eycken A, Guio P. 2002. ESR mapping of polar-cap patches in the dark cusp. Geophys Res Lett 29(10): 1386. DOI: 10.1029/2001GL014087.

Carlson HC, Oksavik K, Moen J. 2008. On a new process for cusp irregularity production. Ann Geophys 26: 2871-2885. DOI: 10.5194/angeo-26-2871-2008.

Carlson H. 2012. Sharpening our thinking about polar cap ionospheric patch morphology, research, and mitigation techniques. Radio Sci 47: RS0L21. DOI: 10.1029/2011RS004946.

Carter BA, Yizengaw E, Pradipta R, Retterer JM, Groves K, Valladares C, Caton R, Bridgwood C, Norman R, Zhang K. 2016. Global equatorial plasma bubble occurrence during the 2015 St. Patrick's Day storm. J Geophys Res Space Phys 121: 894-905. DOI: $10.1002 / 2015 J A 022194$.

Chartier AT, Mitchell CN, Miller ES. 2018. Annual occurrence rates of ionospheric polar cap patches observed using swarm. J Geophys Res Space Phys 123: 2327-2335. DOI: 10.1002/2017JA024811.

Cherniak I, Zakharenkova I, Redmon RJ. 2015. Dynamics of the high-latitude ionospheric irregularities during the 17 March 2015 St. Patrick's Day storm: Ground-based GPS measurements. Space Weather 13(9): 585-597. DOI: 10.1002/2015SW001237.

Cherniak I, Zakharenkova I. 2016. High-latitude ionospheric irregularities: differences between ground- and space-based GPS measurements during the 2015 St. Patrick's Day storm. Earth Planet Space 68(136): 1-13. DOI: 10.1186/s40623-016-0506-1.

Chisham G, Lester M, Milan SE, Freeman MP, Bristow WA, et al. 2007. A decade of the Super Dual Auroral Radar Network (SuperDARN): Scientific achievements, new techniques and future directions. Surv Geophys 28: 33-109. DOI: 10.1007/s10712-0079017-8.

Coley WR, Heelis RA. 1995. Adaptive identification and characterization of polar ionization patches. J Geophys Res 100(A12): 23819-23827. DOI: 10.1029/95JA02700.

Coley WR, Heelis RA. 1998. Structure and occurrence of polar ionization patches. J Geophys Res 103(A2): 2201-2208. DOI: 10.1029/97JA03345.

Coster A, Foster J, Erickson P. 2003. Monitoring the Ionosphere with GPS space weather. GPS World 14(5): 42.

Crain DJ, Sojka JJ, Schunk RW, Zhu L. 1994. Modeling Sun-aligned polar cap arcs. Radio Sci 29(1): 269-281. DOI: 10.1029/ 93RS01512.

Crowley G. 1996. Critical review on ionospheric patches and blobs. In: Review of radio science, 1992-1996, Stone WR (Ed.), Oxford Univ. Press, New York, NY, pp. 619.

Crowley G, Ridley AJ, Deist D, Wing S, Knipp DJ, Emery BA, Foster J, Heelis R, Hairston M, Reinisch BW. 2000. Transformation of high-latitude ionospheric $\mathrm{F}$ region patches into blobs during the March 21, 1990, storm. J Geophys Res 105(A3): 5215-5230. DOI: $10.1029 / 1999 J A 900357$.

Finlay CC, Olsen N, Tøffner-Clausen L. 2015. DTU candidate field models for IGRF-12 and the CHAOS-5 geomagnetic field model. Earth Planet Space 67: 157-189. DOI: 10.1186/s40623-0150274-3.

Foster JC. 1993. Storm-time plasma transport at middle and high latitudes. J Geophys Res 98: 1675-1689. DOI: 10.1029/92JA02032.

Foster JC, Coster AJ, Erickson PJ, Holt JM, Lind FD, et al. 2005. Multi-radar observations of the polar tongue of ionization. $J$ Geophys Res 110: A09S31. DOI: 10.1029/2004JA010928.
Goodwin LV, Iserhienrhien B, Miles DM, Patra S, Meeren C, Buchert SC, Moen J. 2015. Swarm in situ observations of F region polar cap patches created by cusp precipitation. Geophys Res Lett 42: 996-1003. DOI: 10.1002/2014GL062610.

Greenwald RA, Baker KB, Dudeney JR, Pinnock M, Jones TB, et al. 1995. A global view of high latitude convection. Space Sci Rev 71: 761-796. DOI: 10.1007/BF00751350.

Heilig B, Lühr H, Rother M. 2007. Comprehensive study of ULF upstream waves observed in the topside ionosphere by CHAMP and on the ground. Ann Geophys 25: 737-754. DOI: 10.5194/ angeo-25-737-2007.

Hill GE. 1963. Sudden enhancements of F-layer ionization in polar regions. J Atmos Sci 20(6): 492-497. DOI: 10.1175/1520-0469 (1963)020\%3C0492:SEOLII\%3E2.0.CO;2.

Hosokawa K, Tsugawa K, Shiokawa T, Otsuka Y, Nishitani N, Ogawa T, Hairston M. 2010. Dynamic temporal evolution of polar cap tongue of ionization during magnetic storm. J Geophys Res 115: A12333. DOI: 10.1029/2010JA015848.

Jacobsen KS, Andalsvik YL. 2016. Overview of the 2015 St. Patrick's day storm and its consequences for RTK and PPP positioning in Norway. J Space Weather Space Clim 6: A9. DOI: 10.1051/swsc/2016004.

Jin Y, Moen J, Miloch WJ. 2014. GPS scintillation effects associated with polar cap patches and substorm auroral activity: Direct comparison. J Space Weather Space Clim 4: A23. DOI: 10.1051/ SWSC/2014019.

Jin Y, Moen JI, Miloch WJ, Clausen LBN, Oksavik K. 2016. Statistical study of the GNSS phase scintillation associated with two types of auroral blobs. J Geophys Res Space Phys 121: 4679-4697. DOI: $10.1002 / 2016 J A 022613$.

Jin Y, Oksavik K. 2018. GPS scintillations and losses of signal lock at high latitudes during the 2015 St. Patrick's Day storm. J Geophys Res Space. DOI: 10.1002/2018JA025933.

Kersley L, Pryse SE, Wheadon NS. 1988. Small scale irregularities associated with a high latitude electron density gradient: Scintillation and EISCAT observations. J Atmos Sol Terr Phys 50(6): 557-563. DOI: 10.1016/0021-9169(88)90114-6.

Keskinen MJ, Mitchell HG, Fedder JA, Satyanarayana P, Zalesak ST, Huba JD. 1988. Nonlinear evolution of the Kelvin-Helmholtz instability in the high-latitude ionosphere. J Geophys Res 93(A1): 137-152. DOI: 10.1029/JA093iA01p00137.

Krankowski A, Shagimuratov I, Baran L, Epishov I, Tepenitzyna N. 2006. The occurrence of polar cap patches in TEC fluctuations detected using GPS measurements in Southern Hemisphere. Adv Space Res 38: 2601-2609.

Laundal KM, Hatch SM, Moretto T. 2019. Magnetic effects of plasma pressure gradients in the upper F region. Geophys Res Lett 46: 2355-2363. DOI: 10.1029/2019GL081980.

Liu J, Nakamura T, Liu L, Wang W, Balan N, Nishiyama T, Hairston MR, Thomas EG. 2015. Formation of polar ionospheric tongue of ionization during minor geomagnetic disturbed conditions. J Geophys Res Space Phys 120: 6860-6873. DOI: 10.1002/ 2015JA021393.

Liu J, Wang W, Burns A, Solomon SC, Zhang S, Zhang Y, Huang C. 2016. Relative importance of horizontal and vertical transports to the formation of ionospheric storm-enhanced density and polar tongue of ionization. J Geophys Res Space Phys 121: 8121-8133. DOI: $10.1002 / 2016 J A 022882$.

Lockwood M, Carlson HC. 1992. Production of polar cap electron density patches by transient magnetopause reconnection. Geophys Res Lett 19(17): 1731-1734. 
Lomidze L, Knudsen DJ, Burchill J, Kouznetsov A, Buchert SC. 2018. Calibration and validation of swarm plasma densities and electron temperatures using ground-based radars and satellite radio-occultation measurements. Radio Sci 53: 15-36.

Lühr H, Rother M, Maus S, Mai W, Cooke D. 2003. The diamagnetic effect of the equatorial Appleton anomaly: Its characteristics and impact on geomagnetic field modeling. Geophys Res Lett 30(17): 1906. DOI: 10.1029/2003GL017407.

Moen JI, Oksavik K, Abe T, Lester M, Saito Y, Bekkeng TA, Jacobsen KS. 2012. First in-situ measurements of HF radar echoing targets. Geophys Res Lett 39: L07104. DOI: 10.1029/ 2012GL051407.

Noja M, Stolle C, Park J, Lühr H. 2013. Long-term analysis of ionospheric polar patches based on CHAMP TEC data. Radio Sci 48: 289-301. DOI: 10.1002/rds.20033.

Oksavik K, Ruohoniemi JM, Greenwald RA, Baker JBH, Moen J, Carlson HC, ... , Lester M. 2006. Observations of isolated polar cap patches by the European Incoherent Scatter (EISCAT) Svalbard and Super Dual Auroral Radar Network (SuperDARN) Finland radars. J Geophys Res 111: A05310. DOI: 10.1029/ 2005JA011400.

Park J, Ehrlich R, Lühr H, Ritter P. 2012. Plasma irregularities in the high-latitude ionospheric F-region and their diamagnetic signatures as observed by CHAMP. J Geophys Res 117: A10. DOI: 10.1029/2012JA018166.

Pedersen T, Fejer B, Doe R, Weber E. 2000. An incoherent scatter radar technique for determining two-dimensional horizontal ionization structure in polar cap F region patches. J Geophys Res 105 (A5): 10,637-10,655.

Pi X, Mannucci AJ, Lindqwister UJ, Ho CM. 1997. Monitoring of global ionospheric irregularities using the worldwide GPS network. Geophys Res Lett 24(18): 2283-2286. DOI: 10.1029/ 97GL02273.

Pinnock M, Rodger A, Dudeney J, Baker K, Newell P, Greenwald R, Greenspan M. 1993. Observations of an enhanced convection channel in the cusp ionosphere. J Geophys Res 98(A3): 3767-3776.

Prikryl P, Ghoddousi-Fard R, Weygand JM, Viljanen A, Connors M, et al. 2016. GPS phase scintillation at high latitudes during the geomagnetic storm of 17-18 March 2015. J Geophys Res Space Phys 121: 10448-10465. DOI: 10.1002/2016JA023171.

Robinson RM, Tsunoda RT, Vickrey JF, Guerin L. 1985. Sources of F region ionization enhancements in the nighttime auroral zone. $J$ Geophys Res 90(A8): 7533-7546. DOI: 10.1029/JA090iA08p07533.

Rodger AS, Moffett RJ, Quegan S. 1992. The role of ion drift in the formation of ionization troughs in the mid- and high-latitude ionosphere - A review. J Atmos Sol Terr Phys 54(1): 1-30. DOI: 10.1016/0021-9169(92)90082-V.

Rodger AS, Pinnock M, Dudeney JR, Baker KB, Greenwald RA. 1994. A new mechanism for polar patch formation. J Geophys Res 99: 6425-6436.

Spicher A, Clausen LBN, Miloch WJ, Lofstad V, Jin Y, Moen JI. 2017. Interhemispheric study of polar cap patch occurrence based on Swarm in situ data. J Geophys Res Space Phys 122: 3837-3851. DOI: 10.1002/2016JA023750.

Stolle C, Lilensten J, Schlüter S, Jacobi Ch, Rietveld M, Lühr H. 2006a. Observing the north polar ionosphere on 30 October 2003 by GPS imaging and IS radars. Ann Geophys 24: 107-113. DOI: 10.5194/angeo-24-107-2006.

St.-Maurice J-P, Hanson WB. 1982. Ion frictional heating at high latitudes and its possible use for an in situ determination of neutral thermospheric winds and temperatures. $J$ Geophys Res 87: 7580-7602.
Stolle C, Lühr H, Rother M, Balasis G. 2006b. Magnetic signatures of equatorial spread $\mathrm{F}$ as observed by the CHAMP satellite. $J$ Geophys Res 111: A2. DOI: 10.1029/2005JA011184.

Sust M, Zangerl F, Montenbruck O, Buchert S, Garcia-Rodriguez A. 2014. Spaceborne GNSS-receiving system performance prediction and validation. In: NAVITEC 2014, ESA Workshop on Satellite Navigation Technologies and GNSS Signals and Signal Processing, Noordwijk, Netherlands.

Valladares CE, Basu S, Buchau J, Friis-Christensen E. 1994. Experimental evidence for the formation and entry of patches into the polar cap. Radio Sci 29: 167-194.

van den Ijssel J, Forte B, Montenbruck O. 2016. Impact of Swarm GPS receiver updates on POD performance. Earth Planet Space 68: 85. DOI: 10.1186/s40623-016-0459-4.

Wang Y, Zhang Q-H, Jayachandran PT, Lockwood M, Zhang S-R, Moen J, Xing Z-Y, Ma Y-Z, Lester M. 2016. A comparison between large-scale irregularities and scintillations in the polar ionosphere. Geophys Res Lett 43: 4790-4798. DOI: 10.1002/ 2016GL069230.

Weber EJ, Buchau J, Moore JG, Sharber JR, Livingston RC, Winningham JD, Reinisch BW. 1984. F layer ionization patches in the polar cap. J Geophys Res 89: 1683-1694. DOI: 10.1029/ JA089iA03p01683.

Weber E, Klobuchar J, Buchau J, Carlson H Jr., Livingston R, de la Beaujardiere O, McCready M, Moore J, Bishop G. 1986. Polar cap F layer patches: Structure and dynamics. J Geophys Res 91(A11): 12121-12129.

Weber EJ, Kelley MC, Ballenthin JO, Basu S, Carlson HC, et al. 1989. Rocket measurements within a polar cap arc: Plasma, particle, and electric circuit parameters. J Geophys Res 94(A6): 6692-6712. DOI: 10.1029/JA094iA06p06692.

Xiong C, Lühr H, Wang H, Johnsen MG. 2014. Determining the boundaries of the auroral oval from CHAMP fieldaligned current signatures - Part 1. Ann Geophys 32: 609-622. DOI: 10.5194/ angeo-32-609-2014.

Xiong C, Stolle C, Lühr H. 2016. The Swarm satellite loss of GPS signal and its relation to ionospheric plasma irregularities. Space Weather 14: 563-577. DOI: 10.1002/2016SW001439.

Xiong C, Stolle C, Park J. 2018. Climatology of GPS signal loss observed by Swarm satellites. Ann Geophys 36: 679-693. DOI: 10.5194/angeo-36-679-2018.

Zangerl F, Griesauer F, Sust M, Montenbruck O, Buchert B, Garcia A. 2014. SWARM GPS precise orbit determination receiver initial in-orbit performance evaluation. In: Proceedings of the 27th International Technical Meeting of the Satellite Division of the Institute of Navigation (ION GNSS+), Tampa, Florida, 8-12 September, 2014, pp. 1459-1468.

Zhang Q-H, Zhang BC, Lockwood M, Hu HQ, Moen J, Ruohoniemi JM, et al. 2013a. Direct observations of the evolution of polar cap ionization patches. Science 339: 1597-1600. DOI: 10.1126/science.1231487.

Zhang Q-H, Zhang B-C, Moen J, Lockwood M, McCrea IW, Yang H-G, Hu H-Q, Liu R-Y, Zhang S-R, Lester M. 2013b. Polar cap patch segmentation of the tongue of ionization in the morning convection cell. Geophys Res Lett 40: 2918-2922. DOI: 10.1002/grl.50616.

Zhang Q-H, Lockwood M, Foster JC, Zhang S-R, Zhang B-C, McCrea IW, Moen J, Lester M, Ruohoniemi JM. 2015. Direct observations of the full Dungey convection cycle in the polar ionosphere for southward interplanetary magnetic field conditions. J Geophys Res Space Phys 120: 4519-4530. DOI: 10.1002/ 2015JA021172. 
Zhou Y-L, Lühr H, Xiong C, Pfaff RF. 2016. Ionospheric storm effects and equatorial plasma irregularities during the 17-18 March 2015 event. J Geophys Res Space Phys 121: 9146-9163. DOI: $10.1002 / 2016 J A 023122$.
Zou Y, Nishimura Y, Burchill JK, Knudsen DJ, Lyons LR, et al. 2016. Localized field-aligned currents in the polar cap associated with airglow patches. J Geophys Res Space Phys 121: 1017210189. DOI: 10.1002/2016JA022665.

Cite this article as: Xiong C, Yin F, Luo X, Jin Y \& Wan X, 2019. Plasma patches inside the polar cap and auroral oval: the impact on the spaceborne GPS receiver. J. Space Weather Space Clim. 9, A25. 